\title{
Histological Assessment of Fucoidan Gelatine Chitosan Compound Injectable Hydrogel for Bone Regeneration in Wistar Rats
}

\author{
SHRUTHI ESHWAR* ${ }^{*}$ K. KRANTHI ${ }^{1}$, SUPRIYA MANVI, PURNIMAASHOK ${ }^{2}$, Y. S. SURANA ${ }^{2}$, R. SANGEETHA ${ }^{3}$ AND V. JAIN
}

Department of Public Health Dentistry, Karnatak Lingayat Education Society's Institute of Dental Sciences, Yeshwanthpur, Bengaluru 560022, ${ }^{1}$ Department of Periodontics, MS Ramaiah Dental College, Bengaluru 560054, ${ }^{2}$ Department of Pharmacology, Karnatak Lingayat Education College of Pharmacy, Bengaluru 560010, ${ }^{3}$ Department of Oral and Maxillofacial Pathology, Dayanand Sagar College of Dental Sciences, Bengaluru 560078, Karnataka, India

Eshwar et al.: Histological Assessment of Fucoidan Gelatine Chitosan Compound

To evaluate the effectiveness of fucoidan gelatine containing chitosan injectable hydrogel in bone regeneration in rats by histopathological experimentation, a randomized laboratory experimental trial was conducted on 30 Albino Wistar rats. Animals were randomly distributed into 3 groups. Micro defects of 2-3 mm were created in the tibia of each animal and the defects were treated with bone substitutes. Group 1 was treated with $1 \%$ fucoidan- $0.5 \%$ chitosan hydrogel, Group 2 served as control and Group 3 was filled with concentrated growth factor. All the animals were followed up for $28 \mathrm{~d}$ to appreciate wound healing and new bone formation. Fisher's exact test was used to study the difference in bone regeneration and inflammation between the groups. The ratio of new bone per total area was significantly superior in both test groups when compared to the control group at the end of $28 \mathrm{~d}$. New osteoblasts were significantly more in the fucoidan group followed by group $3(p<0.05)$. No statistically significant difference in inflammation status was observed between the 3 groups $(p>0.05)$ at both 14 and $28 \mathrm{~d}$. The presence of fucoidan in the hydrogel significantly contributed to bone regeneration in animals thus proving to be a substitute for tissue engineering.

Key words: Fucoidan-chitosan, injectable hydrogel, osteogenesis, bone regeneration

Bone is a dynamic connective tissue that protects internal organs, helps in locomotion as well as in maintaining homeostasis. Bone defects are a common finding in various systemic and dental disorders. During trauma to the bone, the natural healing is disturbed thus resulting in functional and structural oddness ${ }^{[1]}$. Tissue engineering is at the heart of regenerative medicine and the fastest emerging biomedical field which offers treatment for damaged bone/tissues ${ }^{[2]}$. Regeneration of the lost tooth-supporting structures is mainly dependent on the interplay among scaffold, cells and bioactive cues $^{[3]}$. Regeneration in osseous defects is possible by different grafts, materials, barrier membranes and bone substitutes. All regenerative materials recorded in the literature have known advantages with certain limitations like additional surgery, inadequate bone supply, inappropriate biodegradation, immune response and low tissue compatibility. These limitations have thus, evoked an interest in the development of artificial biomaterials ${ }^{[4]}$.

*Address for correspondence

E-mail: shruthy2015@gmail.com

November-December 2021
Natural polymers have garnered major interest in the field of biomaterials as a result of their biological properties. Preformed scaffolds or hydrogels are primary components of bone tissue engineering. Scaffolds have been widely researched and proved as a promising bone regenerative material. However, certain limitations like poor integration, limited penetration and cost have made a way for use of injectable hydrogels in bone regeneration.

Hydrogels are three-dimensional hydrophilic polymer chains that exhibit excellent mechanical strength, maximum penetration and mimics Extracellular Matrix $(\mathrm{ECM})^{[1]}$. This is an open access article distributed under the terms of the Creative
Commons Attribution-NonCommercial-ShareAlike 3.0 License, which
allows others to remix, tweak, and build upon the work non-commercially,
as long as the author is credited and the new creations are licensed under
the identical terms

Accepted 01 November 2021

Revised 01 July 2021

Received 06 November 2020

Indian J Pharm Sci 2021;83(6):1254-1260 
Chitosan-This natural polymer is considered a boon to regenerative dentistry due to its excellent biological properties. It has anti-inflammatory properties, it is nontoxic, biocompatible, biodegradable and is bioadhesive. Chitosan is extremely flexible and can be transformed into various shapes which adapt well in the tissues. Its good structural properties coupled with good pore size and volume adds to its usefulness in tissue engineering, drug delivery and wound healing. Chitosan is believed to activate osteoblasts, increase osteoconductivity and neovascularisation, thereby leading to increased bone growth ${ }^{[5]}$. However, chitosan lacks bioactivity and degradation and so, requires cross-linkage with synthetic polymers and biocomposites such as alginate, gelatine, hyaluronic acid and growth factors to name a few to enhance its excellent properties. Nanocomposites containing chitosan shows excellent cellular proliferation and mineralization. While chitosan possesses osteoconductive and osteoinductive properties, it lacks the osteogenic potential, to attain chitosan containing fucoidan was developed in this study ${ }^{[6]}$.

Seaweeds, albeit their recent introduction into the market and continues to expand over the world. To our knowledge, there are almost 221 seaweed species worldwide accounting for varied applications in multiple sectors. In India, brown seaweeds are the largest species harvested from the natural beds in both northern and southern parts of the country. The Gulf of Mannar located on the Southeast coast of India is rich in brown seaweeds, particularly belonging to the group Fucales $^{[7]}$.

Fucoidan, a marine brown seaweed, is a sulfated polysaccharide that contains L-fucose and sulfate. It can increase the level of Alkaline Phosphatase (ALP), type-1 collagen expression, osteocalcin and Bone Morphogenetic Protein 2 (BMP-2), and helps in mineral deposition associated with bone mineralization ${ }^{[8]}$.

Studies have been reported that in human adiposederived stem cells, the expression of ALP, type-1 collagen, Runt-related Transcription Factor 2 (RUNX2), osteopontin and osteocalcin were enhanced by fucoidan treatment. Fucoidan has also demonstrated the promotion of osteogenic differentiation in human amniotic fluid stem cells, thereby, proving to be a potential candidate for bone tissue regeneration ${ }^{[9]}$. Sezer et al. confirmed the efficacy of chitosan-fucoidan hydrogel in animals for wound healing and concluded that regeneration on the dermal papillary formation and rapid wound closure was observed in fucoidan-chitosan hydrogels after $14 \mathrm{~d}$ of treatment ${ }^{[10,11]}$. Similarly, a study by Venkatesan et al. compared and concluded that chitosan alginate-fucoidan scaffold was a promising material for bone regeneration ${ }^{[12]}$.

Though few studies have already reported the efficacy of chitosan-fucoidan polymer in wound healing and bone regeneration, the species of fucoidan tested vary. While previous studies have proved the efficacy of Fucus vesiculosus, the present study focuses on fucoidan (Sargassum wightii) as a bone regenerative material and aims to assess the biological properties in its true form (without the addition of any crosslinkers). Hence, considering the biocompatibility, biodegradation, antibacterial nature, film-forming ability and induction of osteogenic differentiation by fucoidan and chitosan, we aimed to conduct a histological assessment of chitosan-fucoidan injectable hydrogel as a catalyst for the bone regeneration process in animals (Wistar rats).

\section{MATERIALS AND METHODS}

\section{Preparation of nanocomposite hydrogel containing chitosan and fucoidan:}

Chitosan, purified by dissolution-precipitation, dialysis and reacetylation up to $85 \%$ degree, was used to produce gels at $37^{\circ}$ following simple neutralization with sodium hydroxide, using very slow gelation and a weak increase in viscosity, to produce a stable formulation for a medical application ${ }^{[13]}$. The material was obtained from Everest Biotech Pharma, Bangalore.

Purified fucoidan from brown seaweed species, Sargassum wightii, was used. The seaweeds were collected, dried overnight and placed in an oven to remove moisture. Dried seaweeds were milled and strained.

Extraction of solvent: Crude extract was prepared by mixing $1 \mathrm{mg}$ of seaweed with $10 \mathrm{ml}$ solvent and stored for $2 \mathrm{~d}$, centrifuged at $10000 \mathrm{rpm}$ for $15 \mathrm{~min}$.

Fucoidan extraction: $20 \mathrm{mg}$ powder was treated with ethanol, stirred for $12 \mathrm{~h}$ and centrifuged for $20 \mathrm{~min}$.

Hydrogel preparation: $1 \mathrm{~g}$ of fucoidan was added to $100 \mathrm{ml}$ of water and stirred for $2 \mathrm{~h}$. $500 \mathrm{mg}$ of chitosan was then added and dissolved followed by the addition of $500 \mathrm{mg}$ of gelatine. This was dissolved at 400 to $2500 \mathrm{rpm}$ in a magnetic stirrer and cooled at room temperature at $25^{\circ}$. The gel solution was continuously stirred for $2 \mathrm{~h}$ until it attained homogeneity and $0.1 \%$ of methylparaben was added to the gel as a preservative. 
Chitosan nanogel was sterilized by autoclaving $\left(121^{\circ}\right.$ for $15 \mathrm{~min}$ ).

\section{Animal experimentation:}

This laboratory experimental study was carried out on 30 Wistar rats after ethical clearance was obtained from the Animal Ethics Committee, Karnatak Lingayat Education (KLE) College of Pharmacy, Bangalore (Proposal No. 01 KLEDCB 2017). 10 adult male Albino Wistar rats weighing 300-350 g were randomly assigned to each of the three study groups: Group 1 (T1): Chitosan (0.5\%)-fucoidan (1\%) hydrogel; Group 2 (C): Control; Group 3 (T2): concentrated growth factor.

The rats were anaesthetized using a mixture of $2 \%$ xylazine hydrochloride and $10 \%$ ketamine hydrochloride. After disinfection of the surgical site using ethanol spray, an incision was made and the periosteum was removed using elevators. On the exposed tibia, a $3 \mathrm{~mm}$ hole was prepared with a micro motor hand piece. The drilled site was irrigated using water to prevent necrosis as well as to wash away any bone debris. The first defects of right leg tibias were filled with sterilized chitosan fucoidan hydrogel and the second defects served as the control. The defects in the left tibia were filled with drops of rat blood that served as the concentrated growth factor. The skin was closed with 4-0 non-absorbable sutures. The animals were followed up for $14 \mathrm{~d}$ and $28 \mathrm{~d}$ to appreciate bone regeneration.

The rats were then transferred to a warm room to recover from anaesthesia and allowed unrestrained activity in cages. They received $0.2 \mathrm{ml}$ of ketoprofen via subdermal injection daily for $3 \mathrm{~d}$ as an analgesic and $0.5 \mathrm{ml}$ of ofloxacin for infection control. The rats in the respective groups were sacrificed and assessed for bone changes with the help of histological examination.

Histological analysis: The tibia was removed and fixated using $10 \%$ formalin and decalcified using $5 \%$ nitric acid by microwave decalcification $\operatorname{method}^{[14]}$. Sections were stained using hematoxylin and eosin for microscopic examination. The slides were examined to appreciate bone healing, osteoblast rimming, inflammation and bone vitality. Subject expert (Pathologist) graded for bone regeneration and inflammation. The grades of 1-3 were given for regeneration wherein 1 -woven bone is seen, 2-woven and lamellar bone are seen, 3-lamellar bone is seen. Inflammation was graded 0-3 based on the presence of inflammatory cells wherein 0: Scattered inflammatory cells; 5 to 10 inflammatory cells focally; Up to 50 inflammatory cells focally;More than 50 inflammatory cells focally. Bone vitality was considered to be present or absent ${ }^{[15]}$.

Histological parameters were analysed statistically using Statistical Package for the Social Sciences (SPSS), version 17.0. The comparison of bone regeneration (osteogenesis phase) and inflammation status between T1, T2 and control groups at different periods were assessed using Fisher's exact test.

\section{RESULTS AND DISCUSSION}

The present study was conducted on 30 Albino Wistar rats for a total period of $28 \mathrm{~d}$. Table 1 and Table 2 show the bone healing status at 14 and $28 \mathrm{~d}$. New bone trabeculae

\section{TABLE 1: BONE HEALING STATUS OF T1, CONTROL} AND T2 SPECIMENS AT $14 \mathrm{~d}$

\begin{tabular}{ccccc}
\hline \multirow{2}{*}{ Period } & $\begin{array}{c}\text { Osteogenesis phase } \\
(\mathrm{n}=10)\end{array}$ & \multicolumn{2}{c}{ Group } & \multirow{2}{*}{ v value $^{\mathrm{a}}$} \\
\cline { 3 - 4 } & G1 & $\mathrm{T} 2$ & \\
& Granulation tissue & 5 & 5 & \\
Fibrosis & 4 & 3 & 0.333 \\
& Woven bone & 5 & 5 & \\
& & $\mathrm{~T} 1$ & Control & \\
14 d $\quad$ Granulation tissue & 5 & 5 & \\
& Fibrosis & 3 & 2 & 0.333 \\
& Woven bone & 5 & 5 & \\
& & $\mathrm{~T} 2$ & Control & \\
& Granulation tissue & 5 & 5 & \\
& Fibrosis & 4 & 2 & 0.083 \\
& Woven bone & 5 & 5 &
\end{tabular}

Note: aFisher's exact test; T1-chitosan (0.5 \%)-fucoidan (1 \%) hydrogel; T2-concentrated growth factor

TABLE 2: BONE HEALING STATUS OF T1, CONTROL AND T2 SPECIMENS AT $28 \mathrm{~d}$

\begin{tabular}{|c|c|c|c|c|}
\hline \multirow{2}{*}{ Period } & \multirow{2}{*}{$\begin{array}{l}\text { Osteogenesis phase } \\
(n=10)\end{array}$} & \multicolumn{2}{|c|}{ Groups } & \multirow{2}{*}{ p value ${ }^{a}$} \\
\hline & & $\mathrm{T} 1$ & T2 & \\
\hline & Granulation tissue & 5 & 4 & \\
\hline & Fibrosis & 0 & 1 & 0.33 \\
\hline & Woven bone & 5 & 3 & \\
\hline & & T1 & Control & \\
\hline & Granulation tissue & 5 & 0 & \\
\hline \multirow[t]{6}{*}{$28 \mathrm{~d}$} & Fibrosis & 0 & 2 & $0.019^{*}$ \\
\hline & Woven bone & 5 & 1 & \\
\hline & & $\mathrm{T} 2$ & Control & \\
\hline & Granulation tissue & 4 & 0 & \\
\hline & Fibrosis & 1 & 2 & $0.023^{*}$ \\
\hline & Woven bone & 3 & 1 & \\
\hline
\end{tabular}

Note: 'Fisher's exact test; T1-chitosan (0.5 \%)-fucoidan (1\%) hydrogel; T2-concentrated growth factor; *level of significance at $p<0.05$ 
lined by active osteoblasts were significantly more in Fucoidan containing chitosan group. The control group showed very little osteoblast rimming at the end of $28 \mathrm{~d}$. No significant differences were found between $\mathrm{T} 1$ and T2 groups regarding the osteoblastic lining of the new bone trabeculae. The connective tissue surrounding the new bone trabeculae ${ }^{[16]}$. was more vascular in the fucoidan containing chitosan group as compared to the control group $(p<0.05)$. All these histologic processes are indicative that the presence of fucoidan in the hydrogel promotes increased osteoblasts which lead to successive bone healing and remineralisation ${ }^{[17]}$.

Inflammatory changes were measured based on the number of infiltrative cells in the high-power field of the microscope on the specimens. Grades of the inflammation were recorded at different stages of the study. No statistically significant difference in the inflammation status between T1, T2 and control groups (p>0.05) at both 14 and $28 \mathrm{~d}$ was observed (fig. 1 and fig. 2).

In this study, the new bone formation was observed along the borders of the surgical defect in all three groups. The ossification process started from the edges of the cortical bone and progressed towards the centre of the defect. Connective tissue callus in the defect area consisted of osteoprogenitor cells, fibers and new blood vessels and guided the formation of new bone trabeculae by intra-membranous ossification. Active osteoblasts synthesizing new bone matrix were numerous at new bone sites, lining the edges of the trabeculae. Hematopoietic precursor cells in the marrow cavity were detected in the slides ${ }^{[18]}$.

Histological data demonstrated that the ratio of new bone per total defect area was significantly higher in both test groups compared to that of the control group

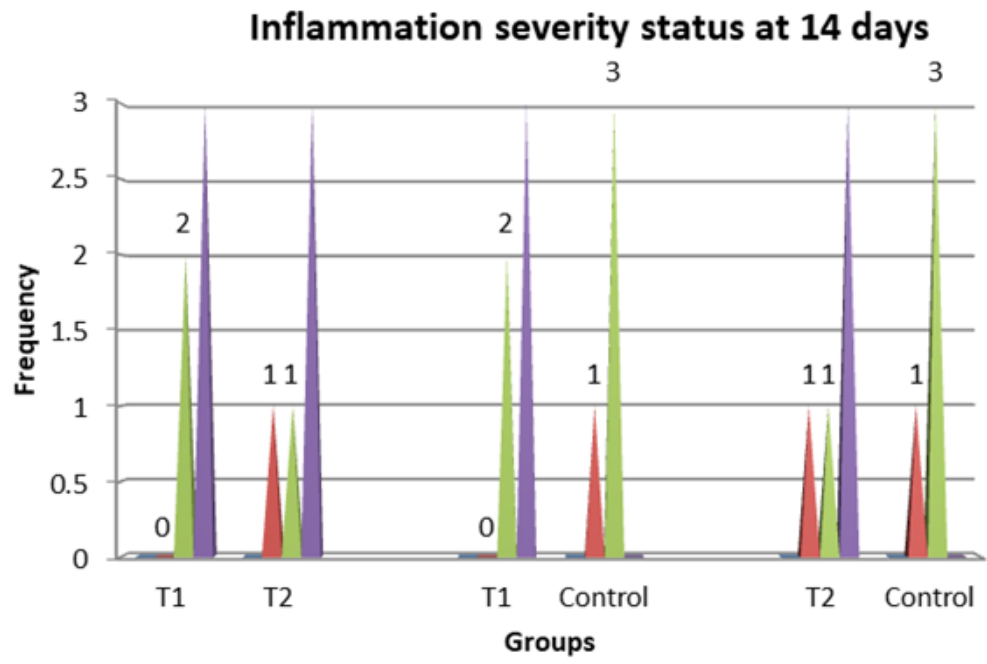

Fig. 1: Distribution of subjects based on inflammation severity status in T1, T2 and control groups at 14 d, T1-chitosan (0.5 $\%)$-fucoidan $(1 \%)$ hydrogel; T2-concentrated growth factor, $(\square)$ No inflammation; $(\square)$ Mild; $(\square)$ Moderate; $(\square)$ Severe

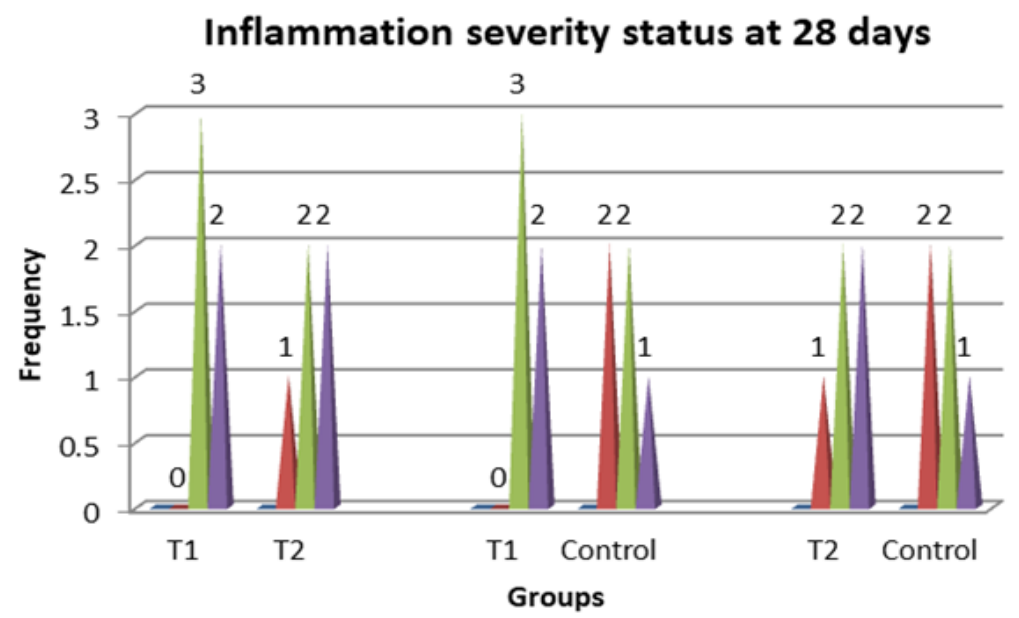

Fig. 2: Distribution of subjects based on inflammation severity status in T1, T2 and control groups at 28 d, T1-chitosan (0.5 \%)-fucoidan (1\%) hydrogel, T2-concentrated growth factor $(\square)$ No inflammation; $(\square)$ Mild; $(\square)$ Moderate; ( $\square$ ) Severe 
$(p<0.001)$ at the end of $28 \mathrm{~d}$. However, no statistically significant difference was observed between the experimental groups.

In Group 1 (T1), fucoidan containing chitosan study showed bone trabeculae ${ }^{[19]}$ with areas of both woven (long arrow) and lamellar bone. Osteoblasts rimming of the bone trabeculae were noted (short arrow). The marrow space contained abundant marrow elements consisting of hematopoietic cells ${ }^{[20]}$. Areas of granulation tissue were noted at the end of $14 \mathrm{~d}$. At the end of $28 \mathrm{~d}$, the section studied showed bone trabeculae with areas of predominantly (long arrow) lamellar bone. Osteoblast rimming of the bone trabeculae was noted (short arrow). The marrow space contained moderate marrow elements consisting of hematopoietic cells (fig. 3A and fig. 3B) $)^{[21]}$.

In Group 2, control group (C), the section studied showed bone trabeculae with areas of both woven (long arrow) and lamellar bone. Bone trabecular distortion was seen (short arrow). Osteoblasts rimming of the bone trabeculae were noted at few places. The marrow space contains moderate marrow elements consisting of hematopoietic cells at $14 \mathrm{~d}$. At the end of $28 \mathrm{~d}$, the section studied showed bone trabeculae with areas of predominantly (long arrow) lamellar bone. Osteoblast rimming of the bone trabeculae was noted (short arrow). The marrow space contained mild marrow elements consisting of hematopoietic cells (fig. 4A and fig. 4B).

In Group 3 (T2): concentrated growth factor, the section studied showed bone trabeculae with areas of both woven (long arrow) and lamellar bone. Bone trabecular distortion was seen (short arrow). Osteoblasts rimming of the bone trabeculae were noted at few places. The marrow space contained abundant marrow elements consisting of hematopoietic cells at end of $14 \mathrm{~d}$. At the end of $28 \mathrm{~d}$, the section studied showed bone trabeculae with areas of predominantly (long arrow) lamellar bone. Osteoblast rimming of the bone trabeculae was noted in a few places (short arrow). The marrow space contained moderate marrow elements consisting of hematopoietic cells (fig. 5A and fig. 5B).

Regeneration of tissue or an organ is possible when a given material meets ideal features like biocompatibility, biodegradable, ease of application, adaptability to the tissues and aids in bone repair. While previous literature claims the use of grafts as an ideal material. However, due to certain limitations of the same, currently natural polymers are being widely experimented with around the globe, as they contribute to excellent biological properties.

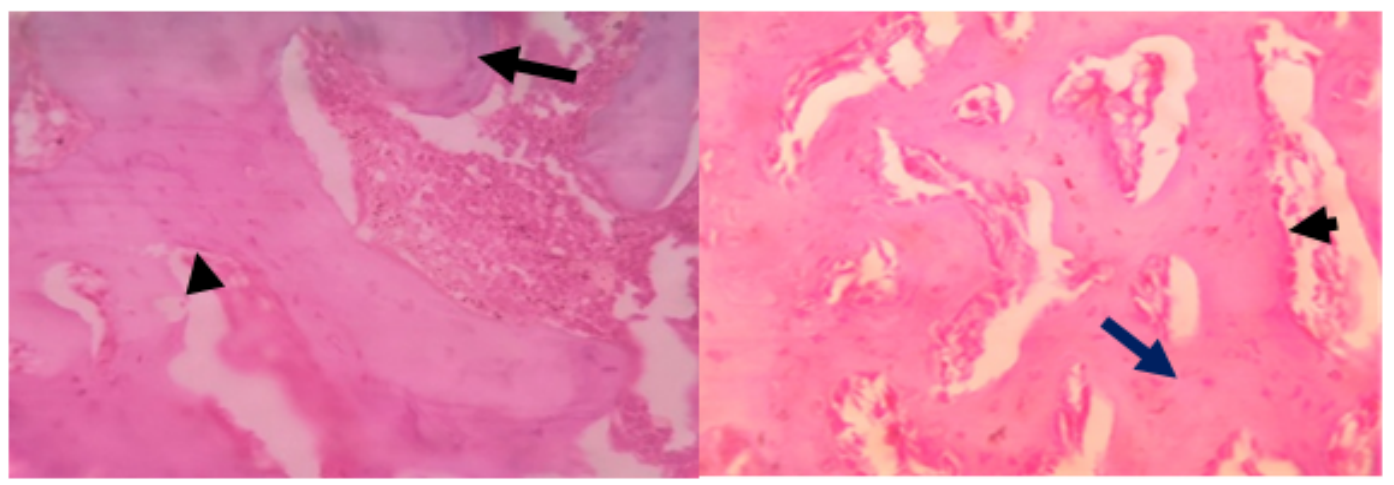

Fig. 3: Histopathological analysis of rat tibia treated with Fucoidan containing chitosan, (A) $14 \mathrm{~d}$ and (B) $28 \mathrm{~d}$
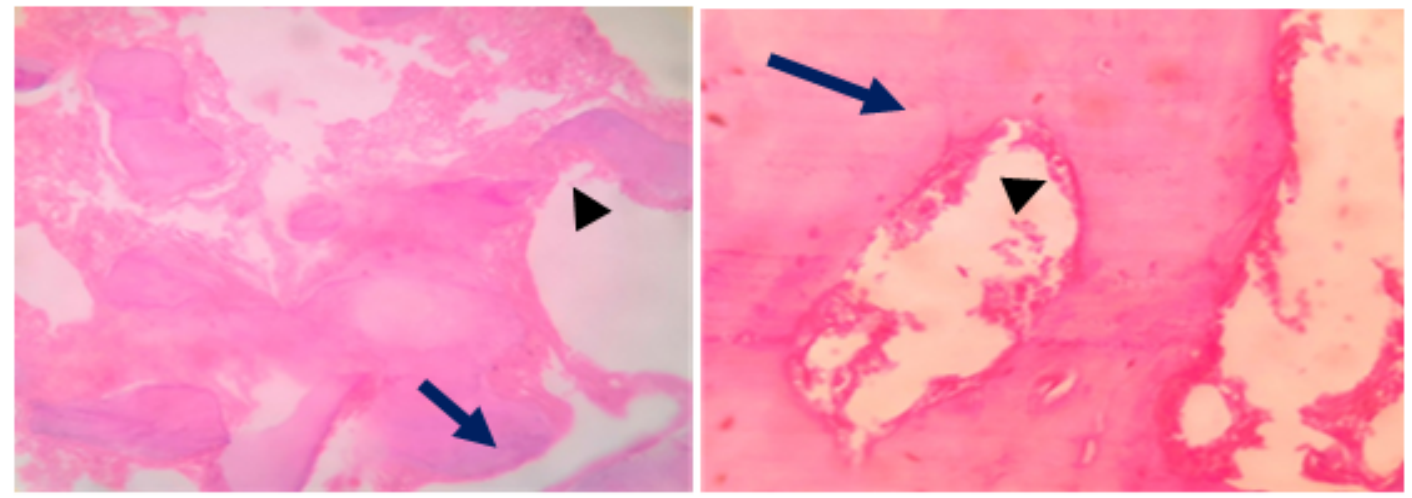

Fig. 4: Histopathological analysis of rat tibia left untreated serving as the control group, (A) $14 \mathrm{~d}$ and (B) $28 \mathrm{~d}$ 


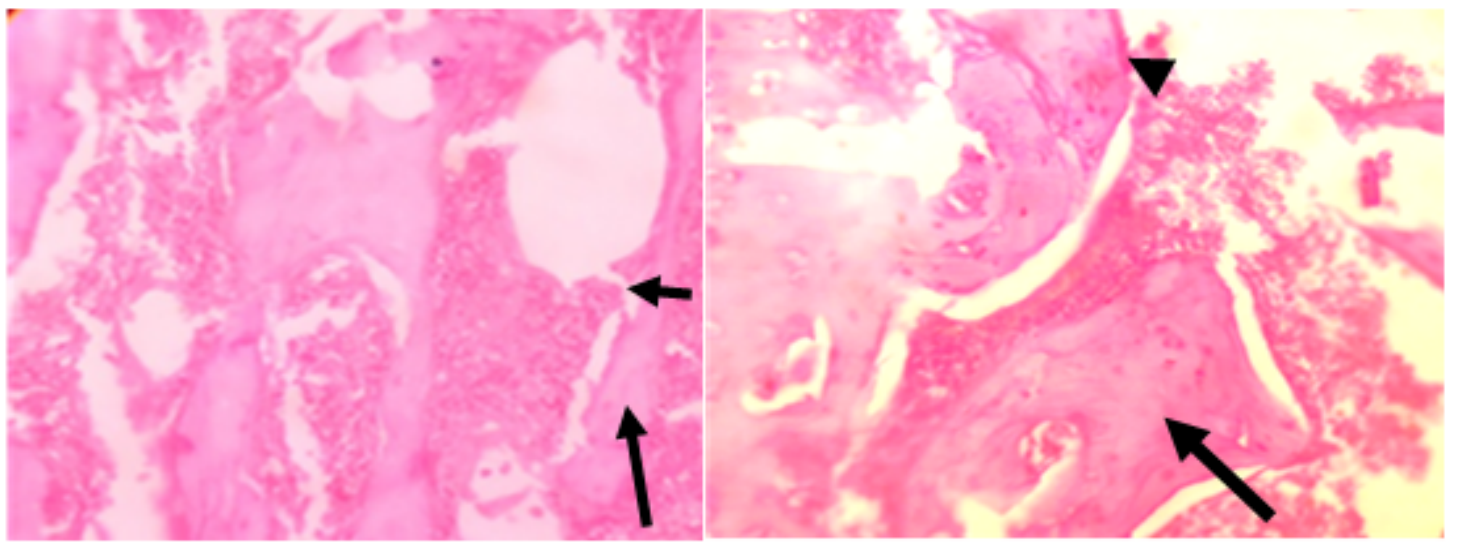

Fig. 5: Histopathological analysis of rat tibia treated with concentrated growth factor, (A) $14 \mathrm{~d}$ and (B) $28 \mathrm{~d}$

Regenerative techniques for bone are generally based on models, which are similar to human anatomy and biology. Although rats are currently the most commonly used animals for in vivo research, there is no simple preclinical model to allow the evaluation of regenerative strategies $^{[22]}$. Different sites are used to evaluate the bone healing of defects created in rats, such as tibia ${ }^{[23,24]}$, calvaria and jaws; each site with its advantages and disadvantages ${ }^{[23,24]}$. The challenge in using the calvarial defect model is the small as per the size of the rat. In the tibia and femur, segmental or cylindrical bone defects can be created. The tibia proximal epiphysis has a medial face that is suitable for inducing bone defects; a sit has a wide and slightly convex surface that is devoid of muscle insertion. Hence in this study, the tibial bone was considered to assess the histological effectiveness of fucoidan containing chitosan and concentrated growth factor as an accelerator of bone regeneration in rat tibia.

In this study, the injectable, thermo-sensitive hydrogel was used which contained 2 natural polymers in their true form without the addition of any composites. The study continued for $28 \mathrm{~d}$ with a follow up on the $14^{\text {th }} \mathrm{d}$ and $28^{\text {th }} \mathrm{d}$. No clinical changes among the animals in all the groups was observed i.e., all animals experienced no weight loss and a reduction in inflammation. The number of blood vessels on both sides declined over time. The tissue repair was not significant in test groups, but significant changes were noticed with the tissue repair as well as in the healing process in the control group. After $1 \mathrm{w}$, Group 1 showed a good amount of cells and initial osteoblast rimming was noticed, whereas the control group showed mild cells with a distortion, indicative of slow healing. Group 1 treated with fucoidan hydrogel showed good signs of healing at the earliest in $14 \mathrm{~d}$ when compared to other groups.
Results of our study are in favour of results of studies conducted by Ardakani et al. and Seyedmajidi et al. ${ }^{[22]}$.

The bone cell count and density increased from d 14 to $\mathrm{d} 28$ due to an increase in osteoblastic activity and bone formation that was promoted by the presence of fucoidan which is known to increase the bone markers thereby helping in regeneration. The difference between the right and left tibias trabeculae thickness was nearly significant and indicated further trabeculae thickness in the placement area of fucoidan containing chitosan group.

Many studies prove the properties of fucoidan and chitosan in bone repair. Fucoidan is known to enhance bone markers and chitosan activates osteoblasts, increases osteoconductivity and neovascularisation leading to increased bone growth. The present study results proved that the defect treated with fucoidan had a good amount of new bone cells when compared to growth factor and untreated site. The difference in trabecular bone thickness between right and left tibias was nearly significant ${ }^{[23]}$.

Daculsi et al. evaluated the feasibility of injectable gels in rabbits and observed that bone substitute had poor mechanical properties and degraded quickly, but had the potential to form new bone rapidly ${ }^{[24]}$. Results of this study also demonstrated the following: The direct contact between bone and biomaterial, fast degradation of its nanoparticles and no remaining material after d 28. The findings of the present study stand apart from various studies conducted so far. This could be attributed to species of the natural polymer used, varied techniques involved and the usage of the polymers in their pure forms without adding any biocomposites. However, morphometric analysis was not performed and the study duration was short, both of which adds to the limitations of this study. 
Fucoidan-gelatine containing chitosan improved biological properties, bioactivity and the presence of osteoblasts at $14 \mathrm{~d}$ when compared with concentrated growth factor.

The presence of fucoidan and chitosan showed were effective regenerative bone substitutes. Thus, the mere presence of fucoidan containing chitosan is promising to renovate the defects caused by trauma, infection and disorders, and leads to successful regeneration of bone.

\section{Conflict of interests:}

The authors declared no conflict of interest.

\section{REFERENCES}

1. Saravanan S, Vimalraj S, Thanikaivelan P, Banudevi S, Manivasagam G. A review on injectable chitosan/beta glycerophosphate hydrogels for bone tissue regeneration. Int $\mathrm{J}$ Biol Macromol 2019;121:38-54.

2. Suzuki JB, Babcock-Goodmans PB. Comparison of clinical healing of human periodontal defects with HTR synthetic grafts. J Dent Res 1989;68:409.

3. Ikinci $\mathrm{G}$, Şenel S, Akıncıbay H, Kaş S, Erciş S, Wilson CG, et al. Effect of chitosan on a periodontal pathogen Porphyromonas gingivalis. Int J Pharm 2002;235(1):121-7.

4. Akıncıbay H, Şenel S, Yetkin Ay Z. Application of chitosan gel in the treatment of chronic periodontitis. J Biomed Mater Res B Appl Biomater 2007;80(2):290-6.

5. Klokkevold PR, Vandemark L, Kenney EB, Bernard GW. Osteogenesis enhanced by chitosan (poly-N-acetyl glucosaminoglycan) in vitro. J Periodontol 1996;67(11):11705 .

6. Li Y, Qian ZJ, Ryu B, Lee SH, Kim MM, Kim SK. Chemical components and its antioxidant properties in vitro: An edible marine brown alga, Ecklonia cava. Bioorg Med Chem 2009;17(5):1963-73.

7. Cho YS, Jung WK, Kim JA, Choi IW, Kim SK. Beneficial effects of fucoidan on osteoblastic MG-63 cell differentiation. Food Chem 2009;116(4):990-4.

8. Crouch SP, Kozlowski R, Slater KJ, Fletcher J. The use of ATP bioluminescence as a measure of cell proliferation and cytotoxicity. J Immunol Methods 1993;160(1):81-8.

9. Sezer AD, Cevher E, Hatıpoğlu F, Oğurtan Z, Baş AL, Akbuğa J. Preparation of fucoidan-chitosan hydrogel and its application as burn healing accelerator on rabbits. Biol Pharm Bull 2008;31(12):2326-33.

10. Sezer AD, Hatipoglu F, Ogurtan Z, Bas AL, Akbuga J. Evaluation of fucoidan-chitosan hydrogels on superficial dermal burn healing in rabbit: An in vivo Study. J Biotechnol 2005:118(1):77.

11. Venkatesan J, Bhatnagar I, Kim SK. Chitosan-alginate biocomposite containing fucoidan for bone tissue engineering. Mar Drugs 2014;12(1):300-16.

12. Qiu Y, Park K. Environment-sensitive hydrogels for drug delivery. Adv Drug Deliv Rev 2001;53(3):321-39.

13. Yang C, Chung D, You S. Determination of physicochemical properties of sulphated fucans from sporophyll of Undaria pinnatifida using light scattering technique. Food Chem 2008;111(2):503-7.

14. Sangeetha R, Uma K, Chandavarkar V. Comparison of routine decalcification methods with microwave decalcification of bone and teeth. J Oral Maxillofac Pathol 2013;17(3):386-91.

15. Neyt JG, Buckwalter JA, Carroll N. Use of animal models in musculoskeletal research. Iowa Orthop J 1998;18:118-23.

16. Kütan E, Duygu-Çapar G, Özçakir-Tomruk C, Dilek OC, Özen F, Erdoğan Ö, et al. Efficacy of doxycycline release collagen membrane on surgically created and contaminated defects in rat tibiae: A histopathological and microbiological study. Arch Oral Biol 2016;63:15-21.

17. Gasparini Ribeiro LL, Bosco AF, Nagata MJ, Nascimento de Melo LG. Influence of bioactive glass and/or acellular dermal matrix on bone healing of surgically created defects in rat tibiae: A histological and histometric study. Int J Oral Maxillofac Implants 2008;23(5):811-7.

18. Nagata MJ, Furlaneto FA, Moretti AJ, Bouquot JE, Ahn CW, Messora MR, et al. Bone healing in critical-size defects treated with new bioactive glass/calcium sulfate: A histologic and histometric study in rat calvaria. J Biomed Mater Res B Appl Biomater 2010;95(2):269-75.

19. Schliephake H, Zghoul N, Jäger V, van Griensven M, Zeichen $\mathrm{J}$, Gelinsky M, et al. Bone formation in trabecular bone cell seeded scaffolds used for reconstruction of the rat mandible. Int J Oral Maxillofac Surg 2009;38(2):166-72.

20. Le Guehennec L, Goyenvalle E, Aguado E, Houchmand-Cuny M, Enkel B, Pilet P, et al. Small-animal models for testing macroporous ceramic bone substitutes. J Biomed Mater Res B Appl Biomater 2005;72(1):69-78.

21. Lahiji A, Sohrabi A, Hungerford DS, Frondoza CG. Chitosan supports the expression of extracellular matrix proteins in human osteoblasts and chondrocytes. J Biomed Mater Res 2000;51(4):586-95.

22. Seyedmajidi M, Rabiee SM, Joorsaraee G, Seyed-Majidi $\mathrm{SK}$, Alaghehmand $\mathrm{H}$, Jamaatloo $\mathrm{N}$, et al. Reaction of rat's connective tissue to injectable glass-ceramic-chitosan nanocomposite. J Maz Univ Med Sci 2014;23(110):200-9.

23. Park YJ, Lee YM, Park SN, Sheen SY, Chung CP, Lee SJ. Platelet derived growth factor releasing chitosan sponge for periodontal bone regeneration. Biomaterials 2000;21(2):1539.

24. Daculsi G, Weiss P, Bouler JM, Gauthier O, Millot F, Aguado E. "Biphasic calcium phosphate/hydrosoluble polymer: a new concept for bone and dental substitution biomaterials". Bone 1999;25(2):59-61. 